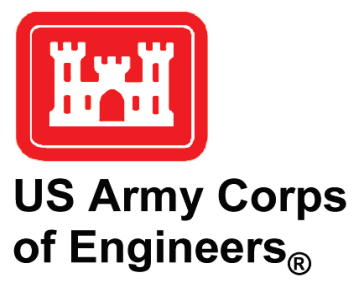

\title{
Coastal Modeling System: Dredging Module Simulation with Multiple Grain Sizes
}

by Christopher W. Reed and Mitchell E. Brown

PURPOSE: This Coastal and Hydraulics Engineering Technical Note (CHETN) describes the use of the Dredging Module (DM) with multiple grain-size sediment transport within the U.S. Army Corps of Engineers (USACE) Coastal Modeling System (CMS). The DM simulates one or more dredging operations during a CMS simulation and provides options for the dredging and placement of material. The DM may be used in studies such as estimating future dredging requirements, evaluating alternative dredging operations, and analyzing morphologic consequences of dredging operations. Simulating multiple sediment grain-sizes within the DM includes representation of the transport of discrete grain size fractions for material placement. An application to an idealized coastal area is provided to illustrate the setup procedure and demonstrate the model capability.

INTRODUCTION: Dredging is a critical function within the USACE Navigation missions. Several hundred million cubic yards of sediment are dredged annually from U.S. ports, harbors, and navigation channels to maintain and improve the nation's navigation system for commercial, national defense, and recreational purposes (USACE 2018). Dredging operations can have a significant impact on coastal morphological evolution (Stark 2012). Hence, the simulation of the coastal morphological features should also include dredging activities. To accurately simulate long-term coastal morphology change extending over multiple dredging cycles, a DM has been developed and implemented into CMS version 5.1 and after.

The CMS, developed by the Coastal Inlets Research Program (CIRP), is an integrated suite of numerical models for simulating water surface elevation, current, waves, sediment transport, and morphology change in coastal and inlet applications and is available within the Surface-water Modeling system (SMS) version 13.0 interface (Buttolph et al. 2006; Sánchez et al. 2011a,b; and Lin et al. 2008). The module directly simulates dredging operations by removing and adding sediment to user-specified dredging and placement areas.

The sediment transport of poorly sorted or nonuniform sediments exhibits differences compared to the transport of uniform sediments. Hiding and exposure (i.e., bed armoring) can have significant impacts on transport rates, bed morphology, bed roughness and dissipation (Wu 2011). The CMS multiple-sized sediment transport model implements the multifraction approach in which the total sediment transport is equal to the sum of the transport of discrete non-cohesive sediment size classes. The DM with multiple grain sizes includes a bed composition scheme that keeps track of the sediment size fractions.

DM OVERVIEW: The DM simulates the dredging and placement of material by simply adjusting the bed elevations of user-defined dredging and placement areas on the CMS-Flow grid. In the previous version, the DM assumes a uniform bed composition and therefore is only recommended 
to be used with a single sediment size class. There are multiple options for controlling how a dredging event is triggered, how the material is dredged, and how the material is placed. If CMSFlow is coupled to CMS-Wave, the updated bathymetry is passed to the CMS-Wave grid at each steering interval. The DM is coupled to the hydrodynamics, waves, and sediment transport through the bed elevations. The dredging simulation can also be configured to simulate the construction of islands created through placement of dredged sediment. It is also possible to represent conditions in which the dredged sediment is placed in upland areas or in areas not represented in the CMS grid domain.

A verification of the DM is provided at https://cirpwiki.info/wiki/CMS/DredgeModule for several idealized test simulations to ensure correctness of input and output as well as mass conservation and documentation of the implementation. Examples are provided in Reed and Sanchez (2016).

The dredging and placement of multiple sediment grain-sizes are an extension of the single-grain size transport approach. In the updated DM, the sediment can be represented by discrete grain size classes, and each size class is eroded, transported, and deposited independently. The grain size classes interact solely in the bed layers. The bed is represented by sediment layers of a specific thickness below the bed surface. The top or surficial upper bed layer is referred to as the mixing layer (often referred to as the active layer), which exchanges the surficial sediments with deposition from the water column. The mixing layer thickness may be set to a constant value (e.g., 0.05 meter $[\mathrm{m}]$ ) or calculated based on the median grain size and bed form size at each cell. The critical shear stress for erosion for each grain size class in the mixing layer is determined using the hiding and exposure approach of $\mathrm{Wu}$ (2014).

Below the mixing layer, additional bed layers are defined and are used to track the fraction of each grain size class in the bed, referred to as the bed composition. All of the bed layers exchange sediment with each other by splitting and merging adjacent layers as their thickness evolves during a simulation due to erosion and deposition. Details on the formulation of multiple grain-size sediment transport can be found at https://cirpwiki.info/images/d/d0/CMS_User_Manual.zip ${ }^{1}$, and guidance on the implementation in SMS is available at http://cirpwiki.info/wiki/CMSFlow Multiple-sized Sediment Transport.

The CMS is a depth-averaged numerical model. Because the effects of three-dimensional processes are not included in the dredging and placement module, dredged cut and placement features are not reflective of realistic morphology around designated operation sites. Therefore, this module is suggested to be applied in cases with non-cohesive sand sized sediment where the morphological characteristics of dredging/placement need not be resolved.

IMPLEMENTATION AND APPLICATIONS: Three CMS simulations have been developed using SMS to demonstrate the implementation of the DM with multiple grain sizes. The user interface for the DM and multiple sediment grain sizes is reviewed here within SMS version 13.0. For earlier SMS versions, additional cards can be added to the bottom of the parameter file to

\footnotetext{
${ }^{1}$ Sánchez, A., L. Lin, Z. Demirbilek, T. Beck, M. Brown, H. Li, J. D. Rosati, W. Wu, and C. Reed. In preparation. Coastal Modeling System User Manual. https://cirpwiki.info/images/d/d0/CMS User Manual.zip
} 
initiate the module. There are no additional parameters required to initiate the implementation other than the standard inputs that would be required for specifying a multiple grain size or dredging simulation independently. Details of the requirements for the DM are available in Reed and Sanchez (2016).

While implementing the coupling, the bed-layer tracking algorithms were modified to assure that sediment mass balance was preserved for multiple grain size classes and bed layers. During typical sediment transport simulations without dredging, the erosion and deposition are relatively slow, and a thin mixing layer and bed layers can be used to retain sufficient resolution of the bed composition. However, during dredging operations the depth of material removed from the bed can exceed typical mixing layer thicknesses. To avoid mass balance errors, the algorithms were modified to merge a sufficient thickness of substrate layers immediately before sediment removal in the dredging process. However, for accurate and robust bed composition simulations, the bed layer thicknesses and total number of layers should be adjusted to cover the anticipated bed elevations changes.

The grid, bathymetry, and dredging and placement areas for the example simulation are shown in Figure 1, which represents a typical offshore region extending 6 kilometers $(\mathrm{km})$ along shore and $3 \mathrm{~km}$ offshore, with water depths on the order of $1.5 \mathrm{~m}$ in the nearshore and $9 \mathrm{~m}$ at the offshore extent. The bed composition is shown in Figure 2. The median grain size (d50) is 0.2 millimeters $(\mathrm{mm})$ in the nearshore and increases linearly offshore, to a value of $3.0 \mathrm{~mm}$.

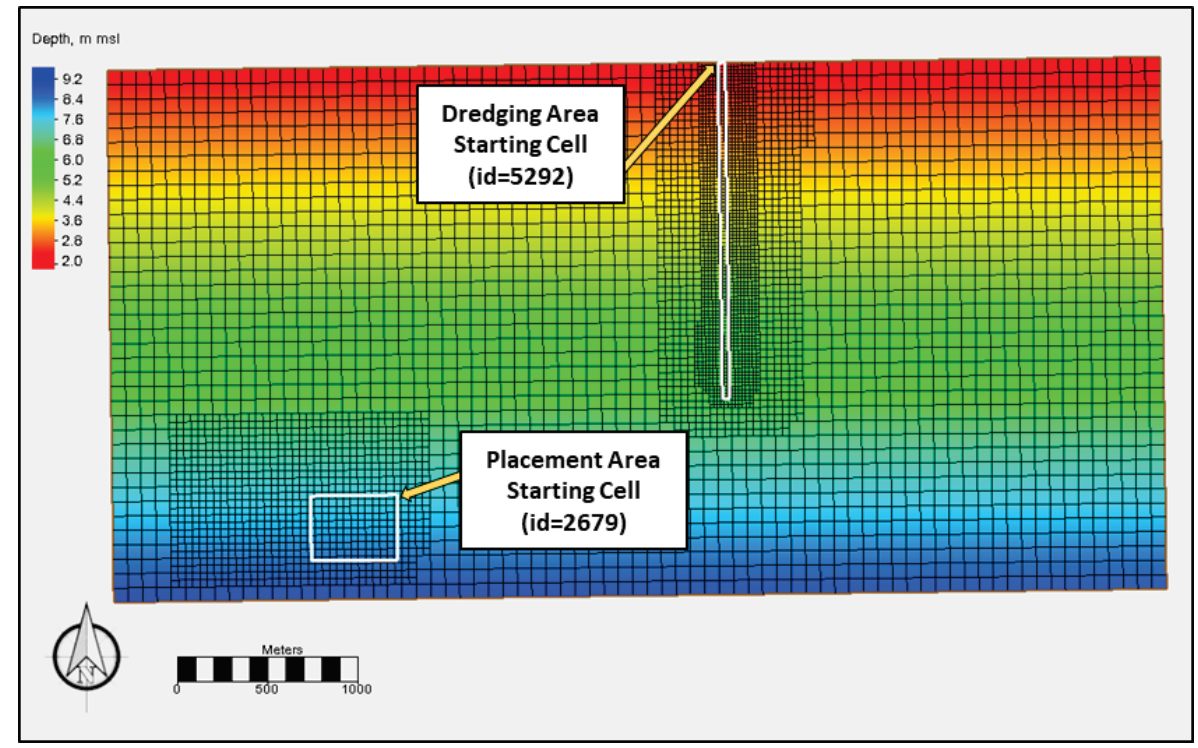

Figure 1. CMS grid, bathymetry and DM information. 


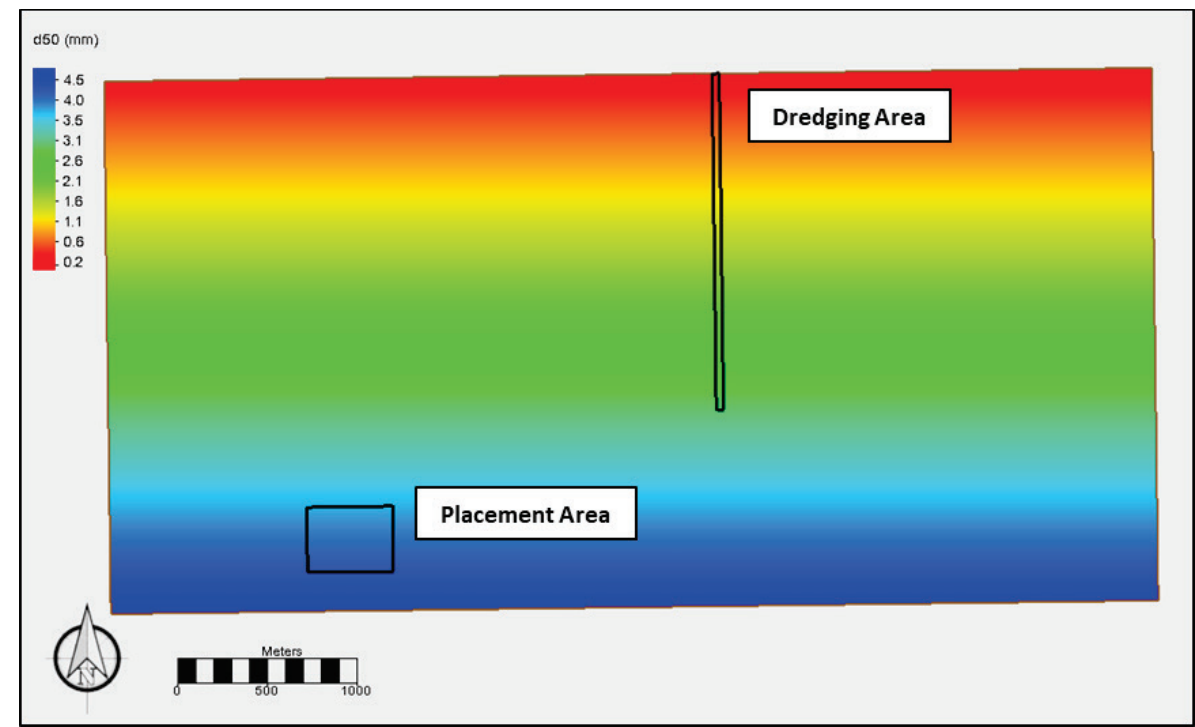

Figure 2. Initial distribution of the d50 values of the bed.

The cards needed to implement the multiple grain size transport are given below and must be added to the CMS-Flow parameter file (.cmcards extension) after the Sediment Transport section:

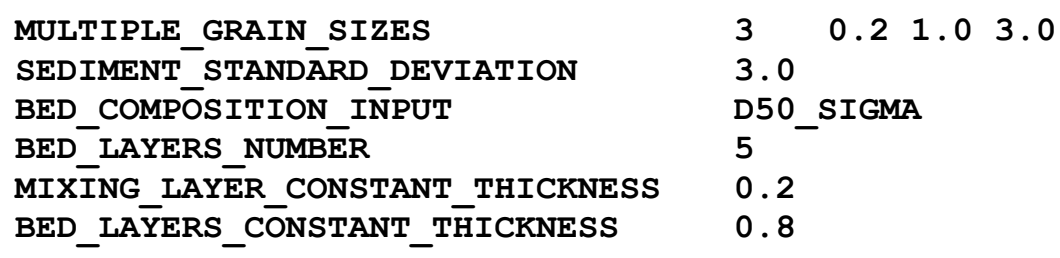

The cards above represent the following example of multiple grain size specification. Three discrete grain size classes are used to represent the sediment distribution: $0.2,1.0$, and $3.0 \mathrm{~mm}$. The standard deviation of the grain size distribution is set to $3.0 \mathrm{~mm}$. These parameters and sediment gradation were specifically selected to demonstrate the impact of the DM on the grainsize distributions.

For the bed composition, a "d50 sigma" input uses a spatially constant geometric standard deviation. The five bed layers are set to a constant thickness and include the mixing layer, which is set to a thickness of $0.2 \mathrm{~m}$.

A new dialog box has recently been added to the SMS 13.0 interface, which allows for user selection of these parameters without the need to edit the CMS-Flow parameter file. The updated dialog box is shown in Figure 3. 


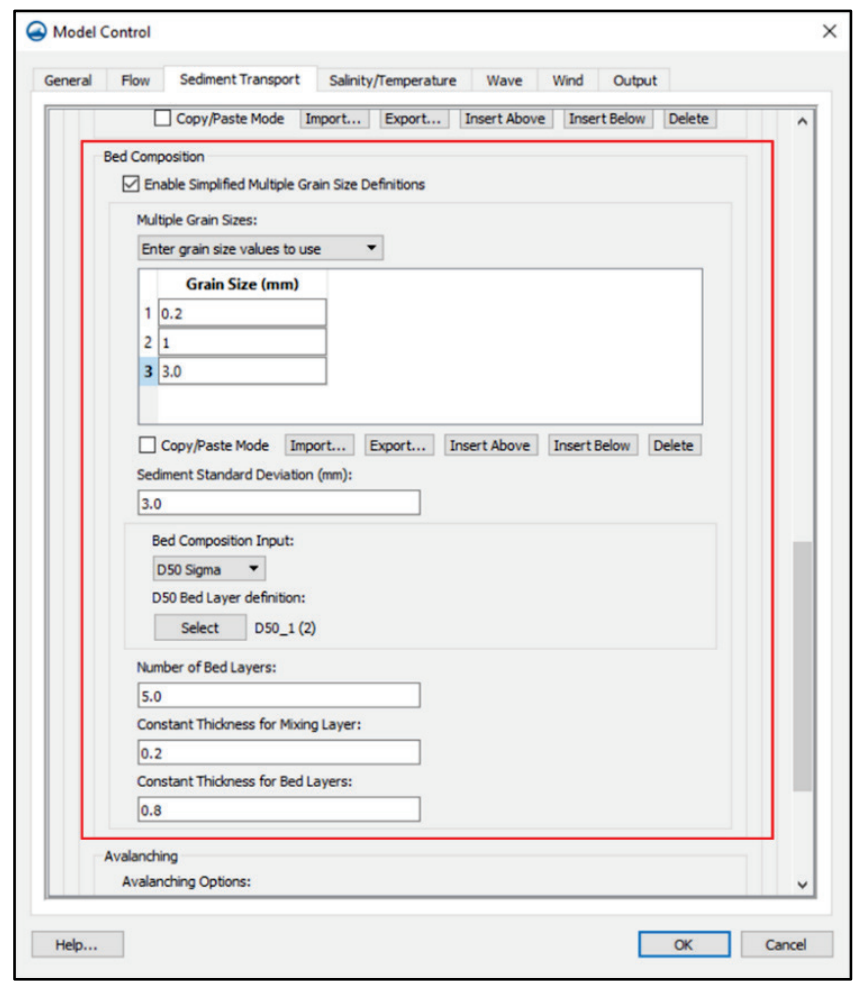

Figure 3. SMS 13.0 interface for multiple-sediment grain sizes (outlined in red).

The dredging and placement areas simulated in Examples 1, 2, and 3 are illustrated in Figure 1. The dredging area is $60 \mathrm{~m}$ wide by $1,880 \mathrm{~m}$ long $\left(\right.$ area $\left.=112,800 \mathrm{~m}^{2}\right)$ extending from the nearshore to a depth of approximately $6.0 \mathrm{~m}$. The dredged depth is specified as $6.0 \mathrm{~m}$. This yields a total dredged volume of $220,465 \mathrm{~m}^{3}$ of bulk material. The dredging rate is specified as $10,000 \mathrm{~m}^{3}$ per day corresponding to a 22-day dredging event. The dredging is specified to start at the nearshore and proceed in the offshore direction by specifying the starting cell locations (as indicated in Figure 1). The placement area is located offshore of the dredging area and is $400 \mathrm{~m}$ by $520 \mathrm{~m}$ (area $=208,000 \mathrm{~m}^{2}$ ). Two dredging methods were tested in Examples 1 and 2, and Example 3 applied a variation of bed layer thickness for comparison to Example 2.

EXAMPLE 1: For the first example simulation, the dredged material was removed and placed using the "SPECIFIED CELL" method in which the starting cell for each operation is specified. In this method, dredging or placement begins at the specified cell and then progresses outward. A dredging rate of $10,000 \mathrm{~m}^{3} /$ day is specified. Removal continues until the trigger depth is reached, and placement continues until the fill reaches a defined upper limit thickness. The dredging and placement then moves to the next closest cell and so on. The trigger depth for dredging is set to $6.0 \mathrm{~m}$, and the upper limit for placement is specified as $1.1 \mathrm{~m}$. One hundred percent of the placement is assigned to the one defined placement zone. Datasets for the dredge and placement areas should be created according to the guidelines given in the initial DM technical note (Reed and Sanchez 2016). 
The cards needed to implement these DM operations are the following:

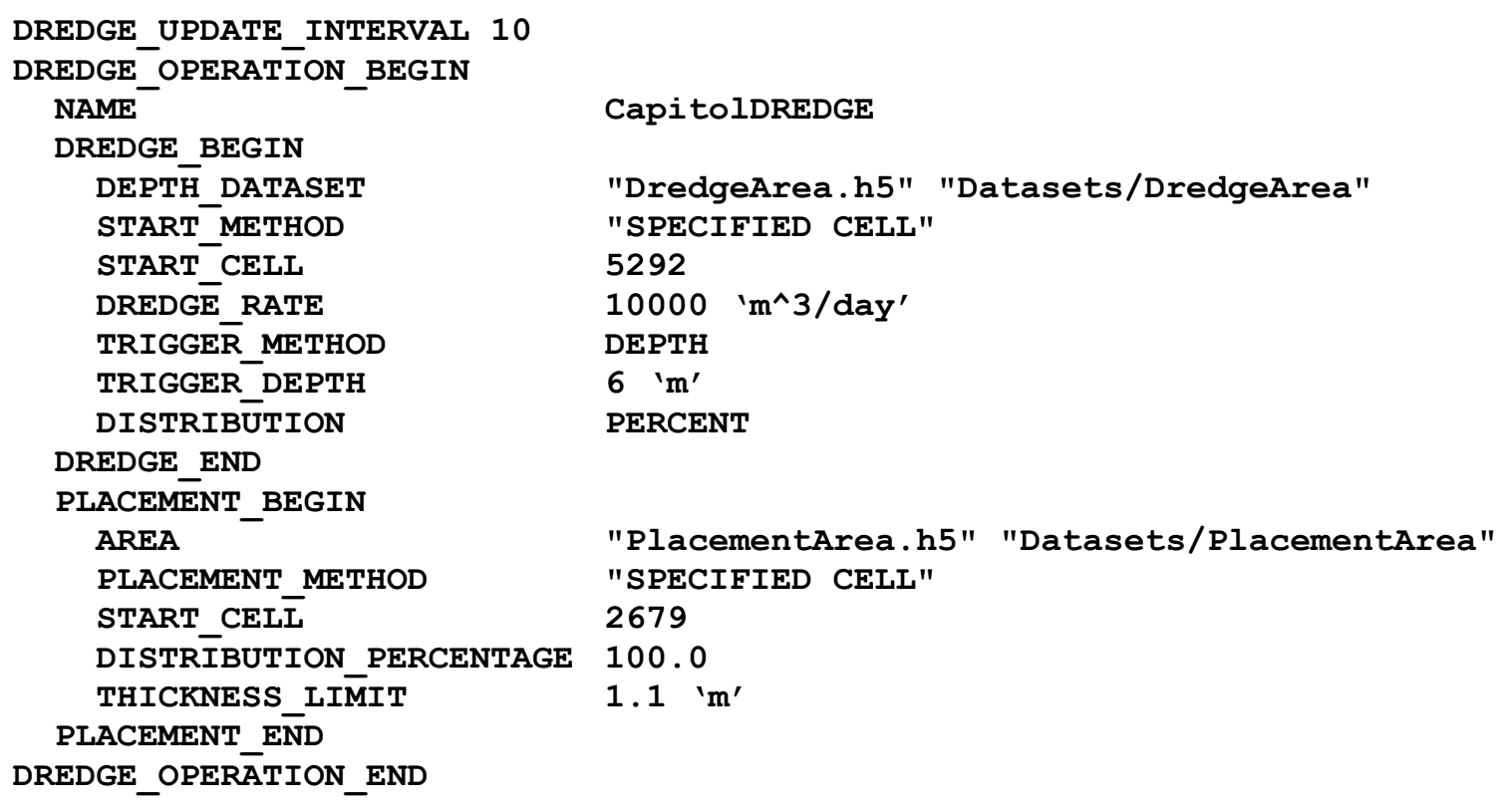

As with multiple sediment grain sizes, an interface has been added to SMS 13.0 that allows for user specification of dredge module parameters without the need to edit the CMS-Flow parameter file. Figures 4 and 5 show the Dredge Definition and Placement Definition pages for this example, respectively.

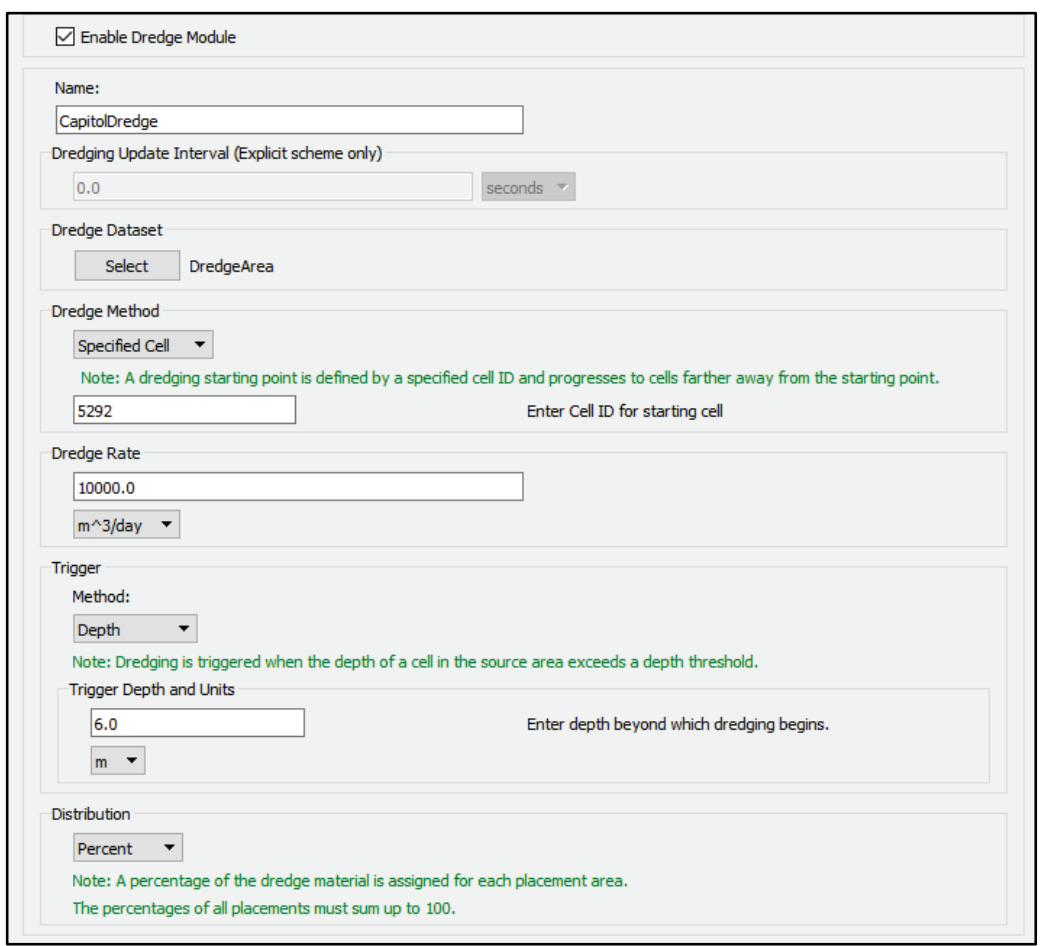

Figure 4. Dredge definition page of the DM interface in SMS 13.0. 


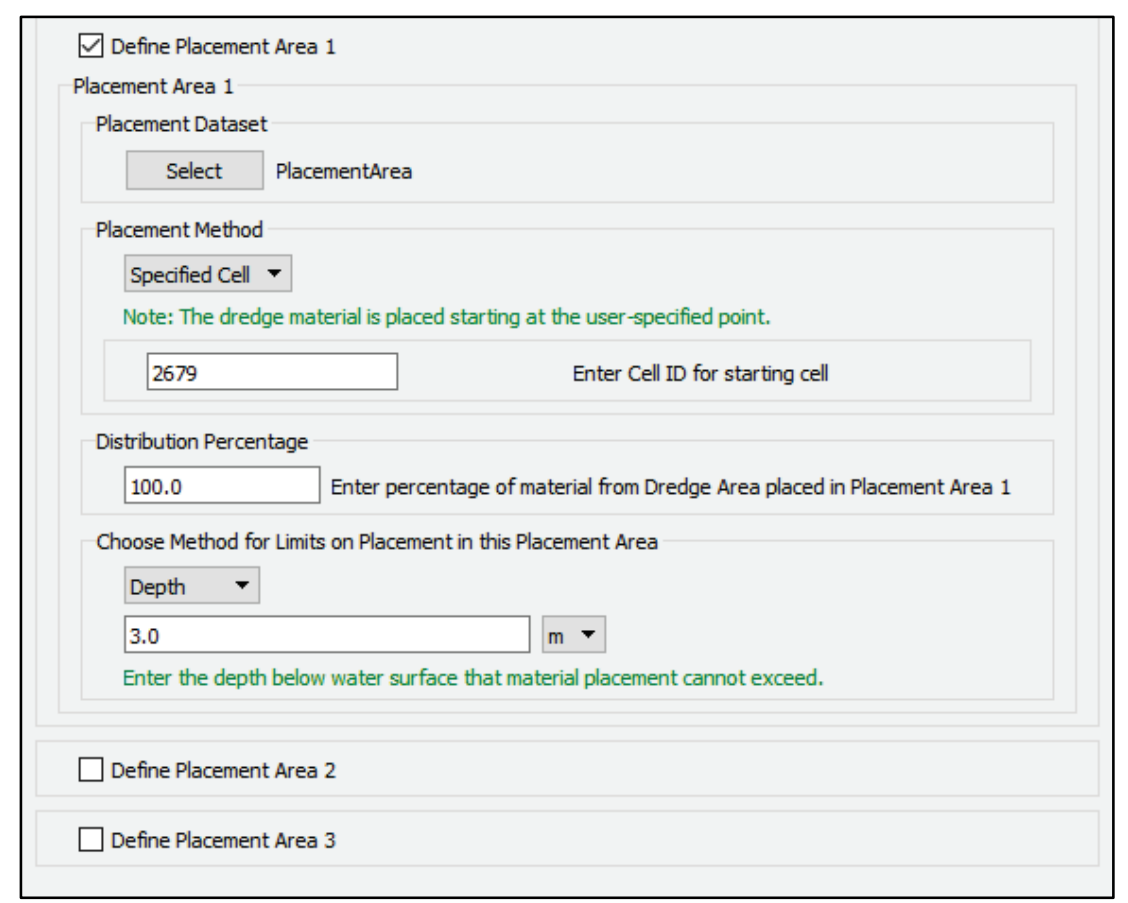

Figure 5. Placement definition page of the DM interface in SMS 13.0.

The bed surface (mixing layer) sediment grain-size distribution at the end of the 22-day simulation is shown in Figure 6. In the dredging area, the sediment d50 is the same as in the initial distribution since the dredging only removes material and the lower bed layers retain their initial sediment distribution.

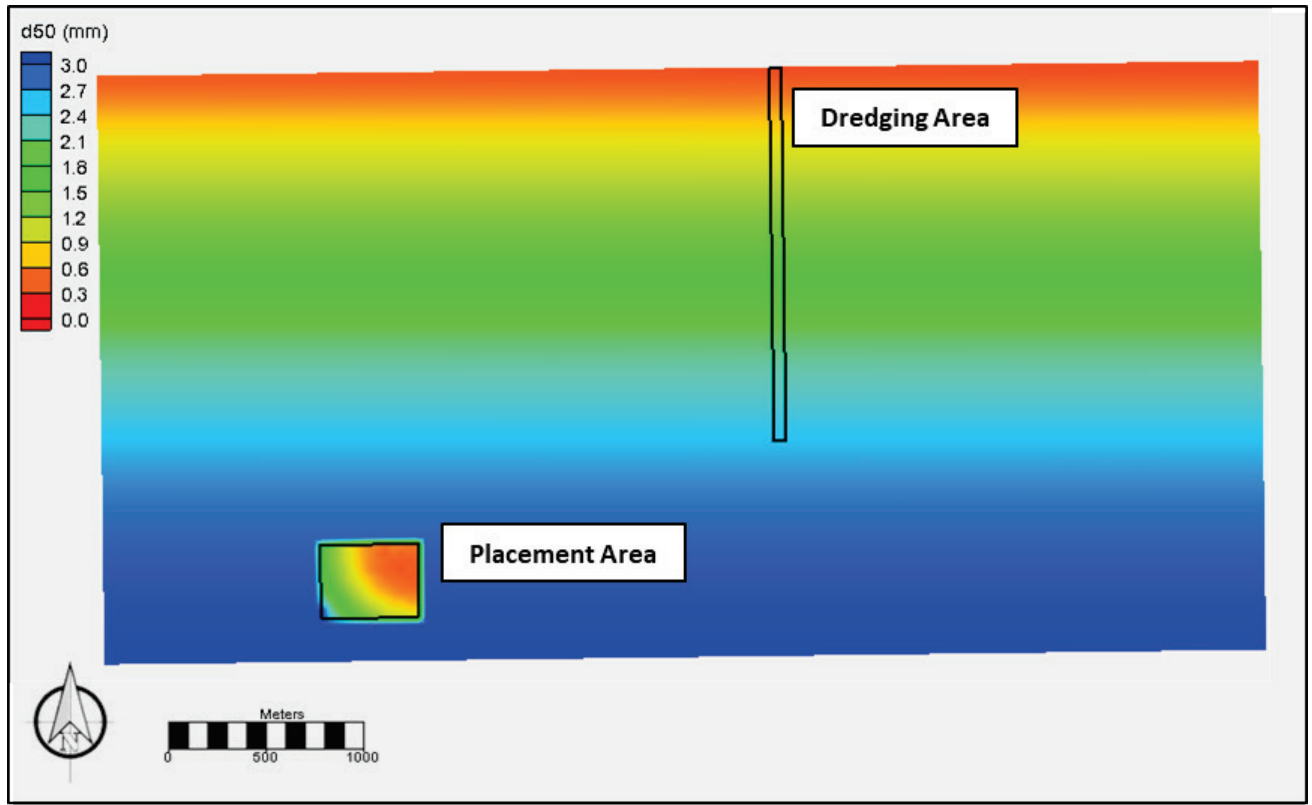

Figure 6. Bed surface d50 distribution after 22 days of simulation for the START_METHOD "SPECIFIED CELL" placement option. 
However, there is a variation in the bed surface sediment grain-size distribution in the placement area. The median grain size is coarser with distance from the starting cell. These variations in the placement area reflect the changes in the sediment source (i.e., dredging area) as the dredging proceeds from the near shore (finer $\mathrm{d} 50$ ) to the offshore (coarser $\mathrm{d} 50$ ).

EXAMPLE 2: In the second simulation, the placement method was changed to UNIFORM with a limit of $3.0 \mathrm{~m}$ for depth in the placement area. The uniform method places material uniformly over every cell in the placement area until the indicated placement limit is reached. The advanced cards used to implement the DM are the following:

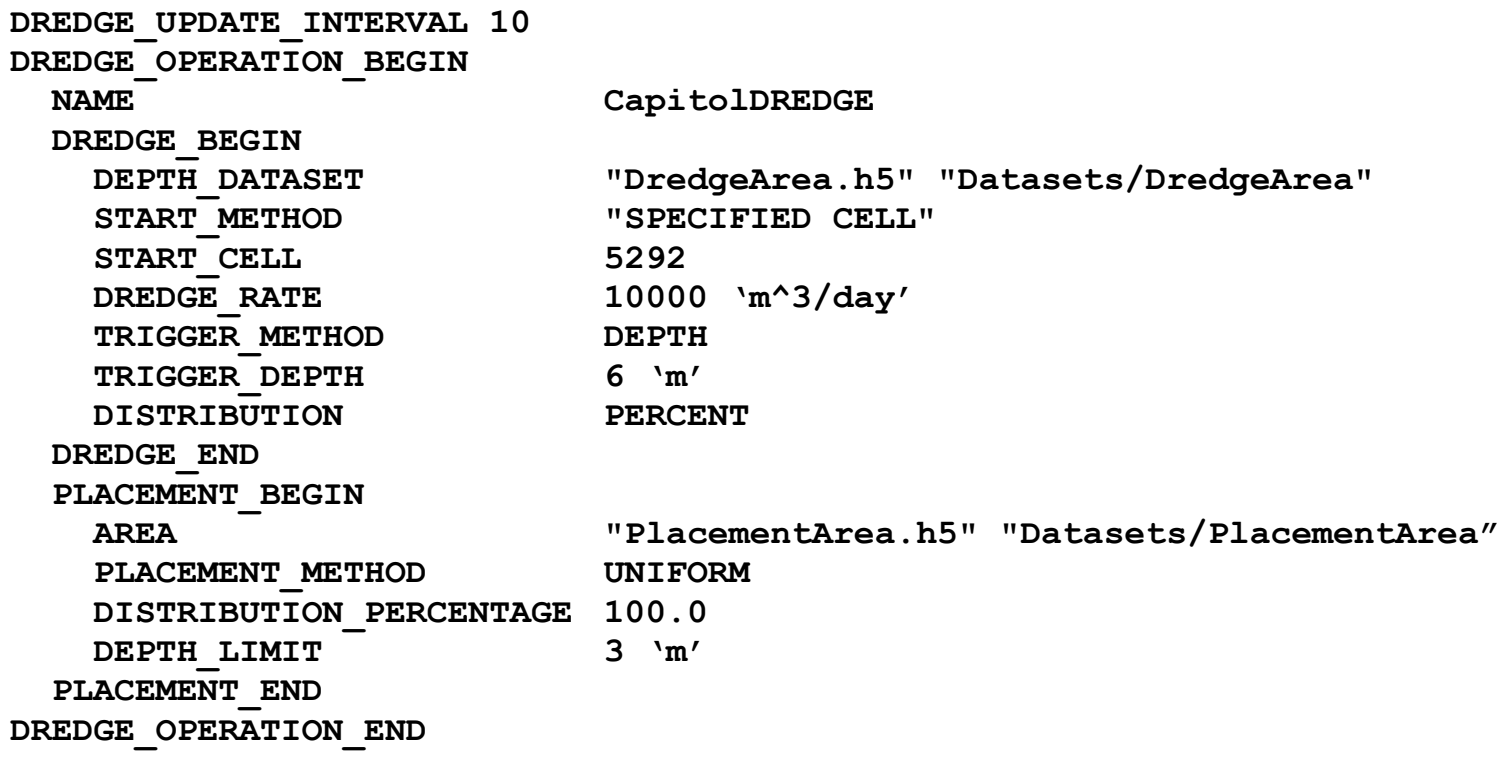

Capi tolDREDGE

"DredgeArea.h5" "Datasets/DredgeArea"

"SPECIFIED CELL"

5292

10000 ' $m \wedge 3 /$ day'

DEPTH

6 ' $\mathrm{m}$ '

PERCENT

"PlacementArea.h5" "Datasets/PlacementArea" UNIFORM

100.0

3 ' $\mathrm{m}$ '

The bed surface (mixing layer) sediment grain-size distribution at the end of the 22-day simulation is shown in Figure 7. As before, the sediment d50 in the dredging area at the end of the simulation is the same as in the initial distribution. 


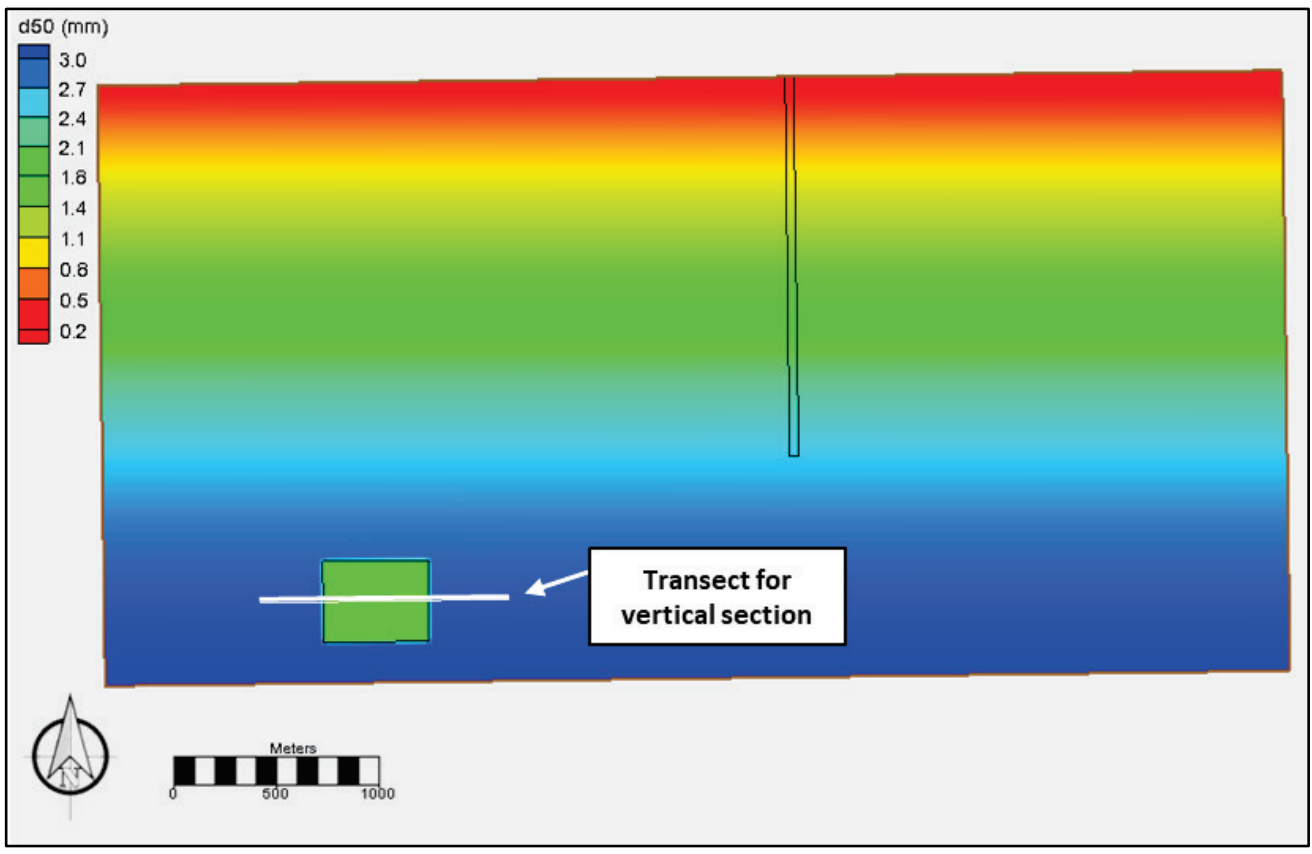

Figure 7. Bed surface d50 distribution after 22 days of simulation for the START_METHOD "UNIFORM" placement option. The white line shows the location of the transect used in additional analyses.

However, the d50 of the bed surface sediment grain-size distribution in the placement area has decreased and is approximately uniform $(\sim 1.5 \mathrm{~mm})$ and reflects the distribution of sediment near the offshore extent of the dredged area. The vertical distribution of the sediment distribution is shown in Figure 8 for the transect shown in Figure 7. The bottom layers have a d50 indicative of the initial sediment composition of the bed. The d50 decreases upward and finally increases again within the top mixing layer. These vertical variations reflect the changing distribution in the source area as the dredging proceeds from the nearshore (finer $\mathrm{d} 50$ ) to the offshore (coarser $\mathrm{d} 50$ ). The discrete points (black dots) represent the top and bottom of each bed layer in each grid cell.

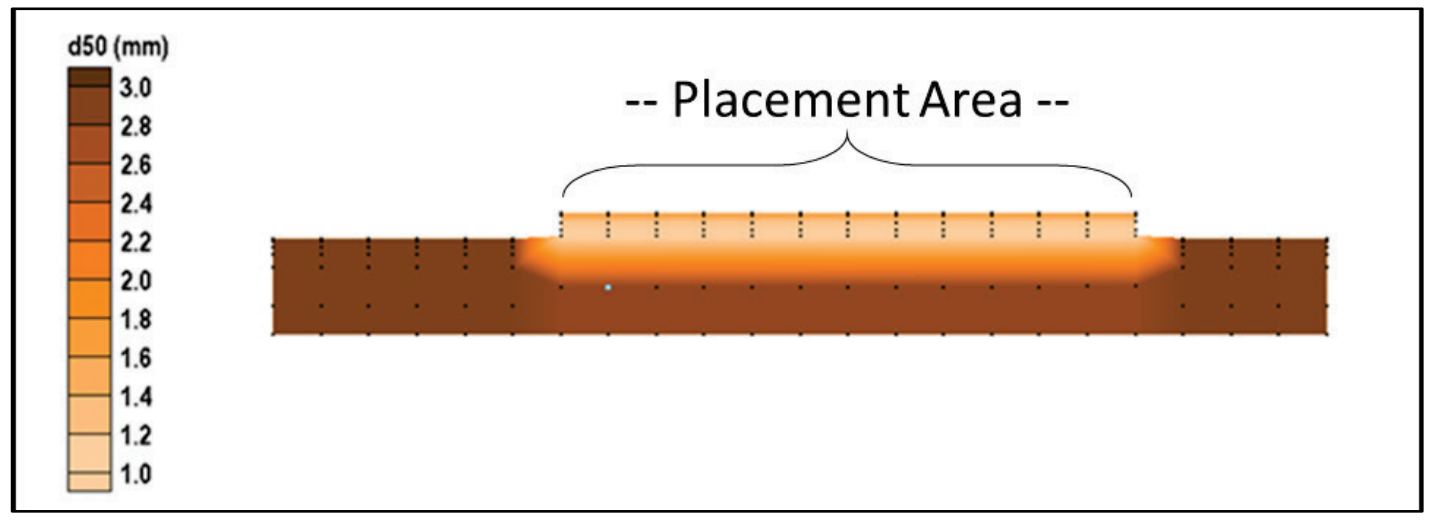

Figure 8. Bed surface vertical d50 distribution after 22 days of simulation for transect shown in Figure 7. 
EXAMPLE 3: A third simulation was conducted to investigate the impact of bed layer thickness on the DM results. This simulation was identical to the second (Figure 7), except that the number of bed layers was increased from the default of 5 to 9 . The mixing layer thickness was set to a constant thickness of $0.1 \mathrm{~m}$, and the remaining bed layer thicknesses were set to $0.2 \mathrm{~m}$. The CMS cards that were modified are listed below:

$\begin{array}{ll}\text { BED_LAYERS_NUMBER } & 9 \\ \text { MIXING_LAYER_CONSTANT_THICKNESS } & 0.1 \\ \text { BED_LAYERS_CONSTANT_THICKNESS } & 0.2\end{array}$

The vertical distribution of the sediment grain size in the placement area is shown in Figure 9 for the same transect in Figure 7.

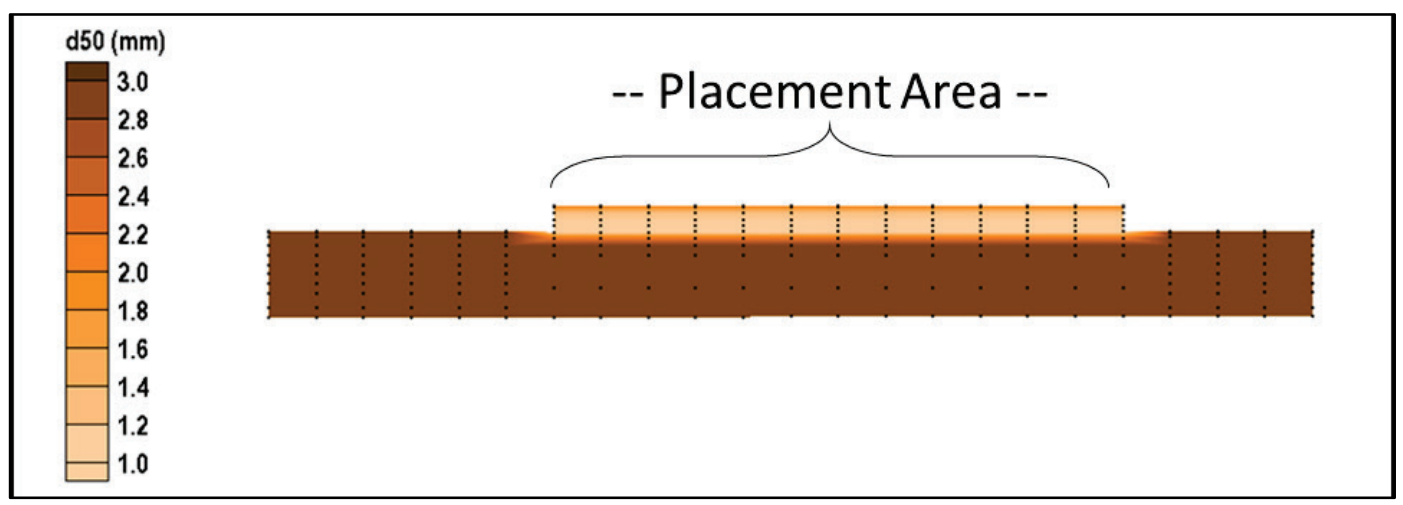

Figure 9. Bed surface vertical d50 distribution after 22 days of simulation for transect shown in Figure 7 using refined bed layer thicknesses.

A plot of the vertical profile of d50 through the center of the placement area is shown in Figure 10 and demonstrates the impact of the bed layer parameters. The d50 is similar through most of the placement area deposit, which extends approximately from 6.8 to $8.1 \mathrm{~m}$ water depth. At the surface, the results with nine bed layers show a higher d50 than that of the five bed-layer simulation $(1.7 \mathrm{~mm}$ vs. $1.5 \mathrm{~mm})$. More notable is the difference near the base of the placement area deposit. There is a gradual increase in sediment grain size with depth for the results with five bed layers reaching the maximum $\mathrm{d} 50$ near a depth of $10 \mathrm{~m}$. Increasing the number of bed layers to nine resulted in a highly resolved decrease in the $\mathrm{d} 50$ at the base of the placement area deposit with the maximum d50 reached just below a depth of $8.25 \mathrm{~m}$. 


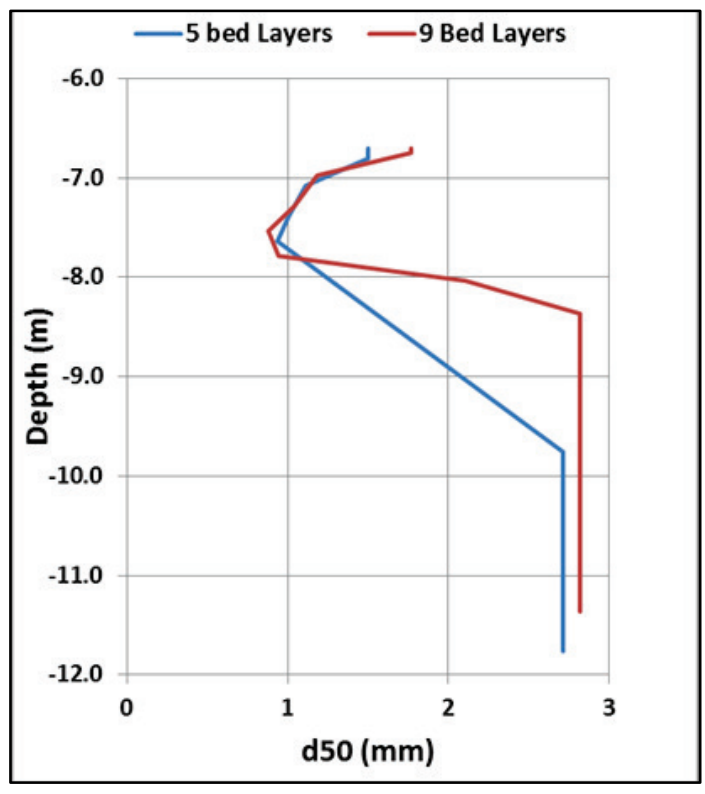

Figure 10. Vertical d50 distribution after 22 days of simulation for point in center of the placement area.

The "smoothing" of the d50 for the case with five bed layers is an artifact of the merging and splitting process bed layer algorithm in the CMS. These results indicate the need to test the bed layering parameter selections to assure that the desired resolution is obtained in the bed.

SUMMARY: The DM was coupled with multiple grain-size non-cohesive sediment transport and implemented in the CMS. The module significantly enhances the capability of the model to support USACE dredging operations at navigation channels by directly simulating dredging and placements of poorly sorted or nonuniform sediment within a CMS simulation. The implementation of the coupled system does not require any additional input from the user other than the standard inputs that would be required for specifying a multiple grain size or dredging simulation independently. The bed layer algorithms were modified to allow for large changes in bed elevation that may occur during dredging simulations. These modifications prevent sediment mass balance violations that might otherwise occur if the bed layer thickness is too small. The implementation procedure for dredging operation and multiple grain sizes was described, and an example simulation for conditions representing an idealized offshore region has been provided to demonstrate the application of two different dredging and placement methods and their results. Future enhancements to the DM include the representation of spatially varying placement thicknesses or depths.

ACKNOWLEDGMENTS: This CHETN was prepared as part of the CMS Work Unit of the USACE CIRP. The technical note was reviewed by the CIRP program manager Tanya M. Beck and Dr. Honghai Li. The authors are thankful for their review comments and suggestions, which improved the content and clarity of this document. Files for the study may be obtained by contacting the authors. 
ADDITIONAL INFORMATION: This CHETN was prepared as part of the USACE CIRP by Dr. Christopher W. Reed, Reed \& Reed, Inc., and Mitchell Brown, U.S. Army Engineer Research and Development Center, Coastal and Hydraulics Laboratory. Questions pertaining to this CHETN may be directed to Mitchell Brown (Mitchell.E.Brown@usace.army.mil) or to the USACE CIRP Program Manager, Tanya M. Beck (Tanya.M.Beck@usace.army.mil). This CHETN should be cited as follows:

Reed, C. W., and M. E. Brown. 2019. Coastal Modeling System: Dredging Module Simulation with Multiple Grain Sizes. ERDC/CHL CHETN-I-98. Vicksburg, MS: U.S. Army Engineer Research and Development Center. http://dx.doi.org/10.21079/11681/33664

\section{REFERENCES}

Buttolph, A. M., C. W. Reed, N. C. Kraus, N. Ono, M. Larson, B. Camenen, H. Hanson, T. Wamsley, and A. K. Zundel. 2006. Two-Dimensional Depth-Averaged Circulation Model CMS-M2D: Version 3.0, Report 2, Sediment Transport and Morphology Change. ERDC/CHL-TR-06-7. Vicksburg, MS: U.S. Army Engineer Research and Development Center.

Lin, L., Z. Demirbilek, H. Mase, J. Zheng, and F. Yamada. 2008. CMS-Wave: A Nearshore Spectral Wave Processes Model for Coastal Inlets and Navigation Projects. ERDC/CHL-TR-08-13. Vicksburg, MS: U.S. Army Engineer Research and Development Center.

Reed, C., and A. Sánchez. 2016. Coastal Modeling System: Dredging Module. ERDC/CHL CHETN I-90. Vicksburg, MS: U.S. Army Engineer Research and Development Center.

Sánchez, A., W. Wu, T. M. Beck, H. Li, J. Rosati III, R. Thomas, J. D. Rosati, Z. Demirbilek, M. Brown, and C. W. Reed. 2011a. Verification and Validation of the Coastal Modeling System, Report 3: Hydrodynamics. ERDC/CHL-TR-11-10. Vicksburg, MS: U.S. Army Engineer Research and Development Center.

Sánchez, A., W. Wu, T. M. Beck, H. Li, J. D. Rosati, Z. Demirbilek, and M. Brown. 2011b. Verification and Validation of the Coastal Modeling System, Report 4: Sediment Transport and Morphology Change. ERDC/CHL-TR-1110. Vicksburg, MS: U.S. Army Engineer Research and Development Center.

Stark, J. 2012. The Influence of Dredging on the Morphological Development of the Columbia River Mouth. M.S. Thesis. Delft University of Technology, The Netherlands.

U.S. Army Corps of Engineers (USACE). 2018. Dredging Cost Analysis-2017. U.S. Army Corps of Engineers Institute for Water Resources, Navigation Data Center - Dredging Information section. https://www.iwr.usace.army.mil/About/Technical-Centers/NDC-Navigation-and-Civil-Works-Decision-Support/

Wu, W., and Q. Lin. 2011. "A Multiple-Sized Transport Formula for Nonuniform Sediments under Currents and Waves." Coastal Engineering Proceedings, No 33 (2012).

Wu, W., and Q. Lin. 2014. "Nonuniform Sediment Transport under Non-Breaking Waves and Currents." Coastal Engineering Journal 90(2014): 1-11. https://doi.org/10.1016/j.coastaleng.2014.04.006

NOTE: The contents of this technical note are not to be used for advertising, publication, or promotional purposes. Citation of trade names does not constitute an official endorsement or approval of the use of such products. 